To appear in: The Interfaces: Deriving and Interpreting (Omitted) Structures, Kerstin Schwabe and Susanne Winkler (eds.), John Benjamins: Amsterdam.

\title{
Subject-Auxiliary Inversion in comparatives and PF output constraints
}

\author{
Jason Merchant \\ University of Chicago
}

This paper establishes the novel generalization that Subject-Auxiliary Inversion (SAI) in comparative clauses requires the co-presence of VP-ellipsis, and argues that this peculiar fact follows from a disjunctive formulation of an ECP that applies at PF. The analysis relies crucially on the presence of an intermediate trace of the $\mathrm{A}^{\prime}$-moved comparative operator at the edge of VP, which is subject to the ECP at PF, and which interacts with the head movement involved in SAI. This trace is unlicensed in structures with I-to-C movement, but VP-ellipsis repairs the violation, providing further evidence that ellipsis can repair otherwise deviant structures."

The object of this paper is to document and assay an explanation of a novel generalization concerning the co-occurrence of Subject-Auxiliary Inversion (SAI; analyzed here as I-to-C movement) and VP-ellipsis in comparative clauses. Although VP-ellipsis is usually optional, in comparative clauses in which I-to-C movement has occurred, it is obligatory. This generalization is stated in (1).

Comparative SAI and VP-ellipsis generalization ${ }^{1}$

I-to-C movement in comparative clauses can occur only if VP-ellipsis has deleted the VP complement to $\mathrm{I}^{0}$.

While this peculiar fact would be easy to encode in grammar formalisms that make direct reference to constructions (such as Construction Grammar or some recent versions of HeadDriven Phrase Structure Grammar; see Goldberg 1995, Sag 1997, Kay and Fillmore 1999), presumably simply by stating the co-occurrence restriction on the type-hierarchies directly (e.g., $\{\mathrm{SAI}\} \cap\{$ comparative wh-movement $\} \cap\{$ non-VP-ellipsis $\}=\varnothing$ ), it poses a much more severe challenge for theories of grammar that attempt to reduce such apparently construction-specific phenomena to general principles that operate across the grammar without restriction. In this paper, I attempt to show that such a general account is possible, and that the seemingly parochial generalization in (1) does not provide evidence against grammatical theories that eschew reference to constructions (such as current work in Minimalism and Optimality Theory; see Chomsky 1995, Grimshaw 1997, Barbosa et al. 1998). In particular, I argue that the peculiar generalization in (1) finds its explanation in the interaction of the properties of head-movement involved in SAI with the licensing of traces of wh-movement, where the licensing in question must be formulated as a kind of ECP applying

\footnotetext{
* I am grateful to Chris Kennedy and Gregory Ward for discussions that stimulated this work and especially for bringing some of the initial data to my attention, though they should not be held guilty in any way for my interpretation of those data or for the present analysis. Thanks also to Anastasia Giannakidou, Jack Hoeksema, Sylvain Neuvel, Eric Potsdam, Chris Potts, Kerstin Schwabe, Susanne Winkler, and Jan-Wouter Zwart for comments and to Jack Hoeksema for making his corpus available to me for searching.

${ }^{1}$ This generalization was noted independently in Potts 2000.
} 
at PF. This analysis lends new support both to the claim that wh-movement out of a VP proceeds via adjunction to that VP, and to the idea that certain types of constraints are operative as static, representational output constraints at the PF-interface.

\section{Establishing the generalization}

I begin by laying out the data that gives rise to the generalization in (1), and continue with a brief comparison to the more well-known case of SAI in matrix wh-questions.

\subsection{Comparatives}

In addition to the usual embedded word order seen in English comparative clauses (CPs selected by than or as), under certain circumstances the highest auxiliary can raise to $\mathrm{C}^{2}{ }^{2}$

(2) a. Abby knows more languages than does her father. (cf. Abby knows more languages than her father does.)

b. Abby can play more instruments than can her father. (cf. Abby can play more instruments than her father can.)

c. Abby is taller than is her father. (cf. Abby is taller than her father is.)

When I raises to $\mathrm{C}$, however, the VP complement to I must be elided, as a comparison of $(2 \mathrm{a}, \mathrm{b})$ with $(3 \mathrm{a}, \mathrm{b})$ shows; when SAI does not take place, VP-ellipsis is not required, however, as shown in (4).

(3) a. *Abby knows more languages than does her father know.

b. *Abby can play more instruments than can her father play.

(4) a. Abby knows more languages than her father knows.

b. Abby can play more instruments than her father can play.

This can be seen clearly also in the contrastive data with stacked auxiliaries in (5)-(7) (a nominal amount comparative, an attributive adjectival comparative, and an adverbial comparative respectively):

(5) a. Abby has been awarded more accolades than has her father (*been awarded).

b. Abby has been awarded more accolades than her father has been awarded.

(6) a. Abby has been awarded a more prestigious accolade than has her father (*been awarded).

b. Abby has been awarded a more prestigious accolade than her father has (been awarded).

(7) a. Abby has been playing piano longer than has her father (*been playing piano).

\footnotetext{
${ }^{2}$ What triggers this movement, and what determines the circumstances under which it can occur, are not germane to the issue that interests me here; see Pollard and Sag 1994:ch. 1, Pesetsky and Torrego 2001 for two recent approaches and references.
} 
b. Abby has been playing piano longer than her father has been playing piano.

It is not the case that SAI in comparatives is possible just in case some kind or other of VP-ellipsis occurs in the comparative clause - the target of VP deletion must be the highest VP, the complement to I. In (8a), for example, the lower VP headed by awarded has been deleted, leaving the higher VP headed by been. In each case, the result is ungrammatical. In the absence of SAI, however, VP-ellipsis is free to target the lower VP; this is shown in the control cases in (9).

(8) a. *Abby has been awarded more accolades than has her father been.

b. *Abby has been awarded a more prestigious accolade than has her father been.

c. *Abby has been playing piano longer than has her father been.

(9) a. Abby has been awarded more accolades than her father has been.

b. Abby has been awarded a more prestigious accolade than her father has been.

c. Abby has been playing piano longer than her father has been.

These data are supported by the results of two corpus searches. The first consisted of a search for SAI in comparative clauses using the AltaVista search engine, and was concluded on 29 October 1999, with the results given in Table 1. The search strings were than does, than do, and than did (other auxiliaries returned too high a rate of false hits to be useful). The number of hits (web pages that contained at least one occurrence of the search string) for each search string is given in column B. The AltaVista search engine, however, only makes available to the user a maximum of 200 web pages, reducing the actual available sample to 200 in each case (the criteria for the selection of the 200 is proprietary information of the AltaVista search engine). A random sample of ten percent of the available pages was examined for the search string. The number of occurrences of the search string that instantiated than with SAI $(N)$ is given in column E (in some cases, a single webpage contained multiple instances of the search string). In each case, the context of the string was examined to determine whether or not VP-ellipsis was co-present, given as $V$ in column F. The resulting percentage is reported in column G. No counterexamples to the generalization in (1) were found.

\begin{tabular}{|lllllll|}
\hline A & B & C & D & E & F & G \\
\hline $\begin{array}{l}\text { Search } \\
\text { string }\end{array}$ & $\begin{array}{l}\text { Number of } \\
\text { hits }\end{array}$ & $\begin{array}{l}\text { Sample } \\
\text { available }\end{array}$ & $\begin{array}{l}\text { Sample } \\
\text { inspected }\end{array}$ & $\begin{array}{l}\text { Number of } \\
\text { than + SAI } \\
(N)\end{array}$ & $\begin{array}{l}\text { Number of } N \\
\text { containing VP- } \\
\text { ellipsis }(V)\end{array}$ & $\begin{array}{l}V \text { as a } \\
\text { percentage } \\
\text { of } N\end{array}$ \\
than does & 45,581 & 200 & 20 & 26 & 26 & $100 \%$ \\
than do & 68,627 & 200 & 20 & 22 & 22 & $100 \%$ \\
than did & 46,086 & 200 & 20 & 21 & 21 & $100 \%$ \\
\hline
\end{tabular}

TABLE 1: AltaVista search for SAI with VP-ellipsis in comparatives

The second corpus search was a search for the same strings in J. Hoeksema's 16 million word database of texts. The number of hits were as follows: 24 occurrences of than 
does, 26 occurrences of than do, and 28 occurrences of than did. And again the results were identical: in all cases, SAI in a comparative clause was accompanied by VP-ellipsis.

\subsection{Matrix wh-questions}

The connection between SAI and VP-ellipsis seen in comparatives contrasts with the state of affairs found in the most common environment for SAI in English: matrix wh-interrogatives, where SAI is obligatory. Here, the restriction noted above for comparatives does not hold no VP-ellipsis is necessary:
a. How many languages does Abby know?
b. How many instruments can Abby play?
c. How many accolades has Abby been awarded?
d. How prestigious an accolade has Abby been awarded?
e. How long has Abby been playing the piano?

There are several other environments in which SAI occurs in standard English, but comparison with such cases is less illuminating, for reasons we will see directly. Consideration of such cases will thus be postponed until below, and I will concentrate first on the asymmetry between the constraints on SAI in comparatives vs. matrix wh-questions.

\section{Intermediate wh-traces and the Empty Category Principle at PF}

We are now in a position to confront the analytical challenge presented by the data above. First, why is VP-ellipsis necessary in comparatives with SAI, and second, why does SAI in matrix wh-questions not have a similar effect? Let us begin by answering the first question. In essence, it seems that the VP deletion is saving an otherwise illicit structure; VP-ellipsis repairs some kind of defect brought about by SAI.

I would like to suggest that this defect is the ill-formedness of the intermediate trace of wh-movement that occurs in the comparative clause. A number of lines of evidence indicate that wh-extraction out of a VP proceeds via adjunction to that VP (see Chomsky 1986, Fox 1999, López and Winkler 2002; cf. also Koster 1978). If this is so, a regular comparative clause such as that in (4b), repeated here in (11a), will have the representation in (11b).

(11) a. Abby can play more instruments than her father can play.

b. $\quad \ldots$ than [CP $O p_{1}$ her father can [vP $t_{1}{ }^{\prime}\left[\mathrm{vP} t_{S U}\right.$ play $\left.\left.\left.t_{1}\right]\right]\right]$

In this structure, the comparative operator (here represented simply as $O p$; see Lechner 1998, Kennedy 2002 for refinements) has been extracted from the object position of play, marked by $t_{1}$, and has moved to specCP by first adjoining to the VP, marked by $t_{1}{ }^{\prime}$.

The intermediate trace $t_{1}{ }^{\prime}$ will be subject to general well-formedness conditions on traces, in particular, it will be subject to the Empty Category Principle (ECP). I modify here the disjunctive approach to the ECP advocated in Chomsky 1981, 1986 and much other work. Crucially, however, this condition applies at PF, and is independent of any condition that may apply at LF as well, about which I will have nothing to say here. Conceptually, this 
approach is reminiscent especially of the proposal in Aoun et al. 1987 (also Rizzi 1990:39 for proper head-government, and cf. Jaeggli 1982), who argue that part of the ECP applies at PF, though the details differ substantially.

\section{The Empty Category Principle at PF (ECP $\mathrm{PF}_{\mathrm{PF}}$ :}

At $\mathrm{PF}$, a trace of $\mathrm{A}^{\prime}$-movement must either be

i. PF-head-governed, or

ii. PF-antecedent-governed

Both disjuncts contain versions of familiar notions, here applied to PF representations. These PF versions of head-government and antecedent-government are defined below; the (i) clauses follow the definitions in Rizzi 1990 in essentials — the innovations are the additional (PF) requirements imposed by the (ii) clauses. I begin with the definition of PF-head-government, given in (13).

$\alpha$ PF-head-governs $\beta$ iff

i. $\quad$ a. $\quad \alpha$ is a head, and

b. $\quad \alpha$ c-commands $\beta$, and

c. $\quad \alpha$ respects Relativized Minimality wrt $\beta$, and

ii. $\quad \alpha$ is PF-active

(14) A link $\alpha_{i}$ in a chain $\left\langle\alpha_{1}, \ldots, \alpha_{n}\right\rangle$ is PF-active iff $\alpha_{i}$ is the link at which lexical insertion occurs

The idea in the definition in (14) is that the PF interface privileges one copy $-\alpha_{i}-$ of a moved element for lexical insertion (in the sense of Halle and Marantz 1993) over other links in the chain formed by movement (the notion 'chain' being only a derivative one, presumably reducible to a consequence of the definition of Move); the features of $\alpha_{i}$ are said to be active at PF (note that this does not entail that this element will be pronounced, given the existence of null lexical items such as null operators, null $\mathrm{I}^{0}$, null $\mathrm{D}^{0}$, etc.). How this computation is effected is not relevant here (but see Richards to appear for one theory of this selection); in general, $\alpha_{i}$ in (14) will be the head of the chain in the cases of present interest. ${ }^{3}$

The definition of PF-antecedent-government is given in (15).

$\alpha P F$-antecedent-governs $\beta$ iff

i. $\quad$ a. $\quad \alpha$ and $\beta$ are co-indexed, and

b. $\quad \alpha$ c-commands $\beta$, and

c. $\quad \alpha$ respects Relativized Minimality wrt $\beta$, and

ii. $\quad \alpha$ is PF-visible

\footnotetext{
${ }^{3}$ The notion of PF-active bears some similarity to Aoun et al.'s (1987) notion of 'PF-visible', though their definition picks out a slightly different class of elements, those that either are pronounced or bear certain kinds of indices (see Aoun et al. 1987: 539, 546). Cf. also Chung's 1991:120 definition of 'strong' head governors (those that either are pronounced or are an element of $\{\mathrm{V}, \mathrm{A}, \mathrm{Infl}\}$ ).
} 
I understand having phonetic exponence as meaning that the element in questioned is pronounced (cf. the equivalent notion of having a phonetic matrix). In the present cases of interest, wh-operators, the notion corresponds exactly to the traditional distinction between overt and empty (or null) operators; only overt operators can satisfy clause (ii) or the $\mathrm{ECP}_{\mathrm{PF} \cdot}{ }^{4}$

In an example such as (11) above, then, these definitions will have the following consequences. In (11b), the lower trace of wh-movement $t_{1}$ is PF-head-governed by plays: plays is a head, c-commands $t_{1}$, no other head intervenes, and at PF, it forms a singlemembered chain, and lexical insertion targets it. The intermediate trace of movement, $t_{1}{ }^{\prime}$, is PF-head-governed by the modal can in $\mathrm{I}^{0}$ : can is a head, c-commands $t_{1}{ }^{\prime}$, no other head intervenes, and lexical insertion targets it at PF. Therefore, both traces in (11b) satisfy the $\mathrm{ECP}_{\mathrm{PF}}$, by virtue of satisfying clause (i) of (12). ${ }^{5}$

Consider now what happens when SAI occurs, as in (3b), repeated here in (17a).

$$
\begin{aligned}
& \text { a. *Abby can play more instruments than can her father play. } \\
& \text { b. } \left.\left.\quad \ldots \text { than [CP } O p_{1} \text { can [IP her father } t_{\text {can }}\left[\mathrm{VP} t_{1}{ }^{\prime}\left[\mathrm{VP} t_{S U} \text { play } t_{1}\right]\right]\right]\right]
\end{aligned}
$$

This example has the structure in (17b), parallel to (11b) above except for the presence of Ito-C movement. I-to-C movement in the comparative clause moves the modal can out of the IP, forming the chain $\left\langle\right.$ can, $t_{c a n}>$ (again, presumably independent principles determine that the higher copy is pronounced in this structure, and that the lower copy remains unpronounced, signalled here with the traditional $t$ ). While the lower trace $t_{1}$ satisfies the $\mathrm{ECP}_{\mathrm{PF}}$ as above, the I-to-C movement changes the licensing status of the intermediate trace $t_{1}{ }^{\prime}$ : the lower copy of can, $t_{c a n}$ in $\mathrm{I}^{0}$, does not PF-head-govern $t_{1}{ }^{\prime}$ because it is not PF-active (the higher copy is, in $\mathrm{C}$ ). This means that the $\mathrm{ECP}_{\mathrm{PF}}$ in (12) cannot be satisfied via clause (i) as it was in (11).

The other possibility for satisfying the $\mathrm{ECP}_{\mathrm{PF}}$ is via clause (ii) of (12), which requires PF-antecedent-government. While $O p$ in specCP does antecedent-govern $t_{1}{ }^{\prime}$, it does not satisfy the crucial PF-requirement in (15ii): $O p$ is not PF-visible, that is, pronounced (perhaps for substantive reasons, as explored in Lechner 1998 and Kennedy 2002). Thus the intermediate trace of $O p$ violates the $\mathrm{ECP}_{\mathrm{PF}}$ and (17a) is correctly ruled out.

We are now in a position to account for the otherwise puzzling generalization that SAI is possible in comparatives just in case VP-ellipsis has targeted the VP sister to $\mathrm{I}^{0}$, as established in section 1.1. I assume that ellipsis is deletion of a constituent at PF (see Merchant 2001 for extensive discussion and references); for VP-ellipsis, this means that a VP is deleted in the derivation from Spell-Out to the PF representation. For a non-comparative

\footnotetext{
${ }^{4}$ The notions of PF-visibility and PF-activeness clearly have much in common; whether they could be collapsed entirely, at least for case of heads, depends on details of the analysis of Affix-hopping and complementizer 'deletion' phenomena that go beyond the bounds of the present paper.

${ }^{5}$ Similarly, presumably, when $\mathrm{I}^{0}$ has no pronounced content, as in (4a), where no do-support is necessary; exactly how lexical insertion spells out the information in $I^{0}$ on the verb in such cases is a topic of much debate (see e.g. Bobaljik 1995). The present cases are incompatible with literal I-to-V lowering analyses - what is clear is that in these cases $\mathrm{I}^{0}$ must not move, so it is the features of $\mathrm{I}^{0}$, though not necessarily pronounced in $\mathrm{I}^{0}$, that are active at the PF interface, and operate in the desired manner for purposes of the $\mathrm{ECP}_{\mathrm{PF}}$.
} 
example such as (18a), this deletion is represented as in (18b), where strikethrough indicates deleted material, inactive at PF.

(18) a. Abby can play the piano, but her father can't.

b. Abby can play the piano, but her father can't $\mathrm{fvP}_{\mathrm{f}} t_{s u}$ play the piano].

Consider now what effect such deletion will have in comparatives in which SAI has occurred, such as (2b), repeated here.

Abby can play more instruments than can her father.

In such an example, wh-movement leaves an intermediate trace adjoined to the highest VP, as we have seen. But in addition, VP-ellipsis has applied, deleting the highest VP segment. The resulting PF structure is given in (20).

$$
\left.\left.\ldots \text { than [CP } O p_{1} \text { can [IP her father } t_{c a n} \mathrm{fvP}_{\mathrm{vP}} t_{1}{ }^{\prime} \mathrm{fvP}_{\mathrm{vP}} \boldsymbol{t}_{S u} \mathrm{play} t_{1} \mathrm{H}\right]\right]
$$

Because VP-ellipsis has deleted the intermediate trace $t_{1}{ }^{\prime}$ contained in the deleted VP, $t_{1}{ }^{\prime}$ will not violate the $\mathrm{ECP}_{\mathrm{PF}}$; deletion removes the offending trace from the $\mathrm{PF}$-object considered by the $\mathrm{ECP}_{\mathrm{PF}}$, since the $\mathrm{ECP}_{\mathrm{PF}}$ is a well-formedness condition applying at the PF interface. The logic here is very similar, then, to the logic applied to other PF violations voided by ellipsis as discussed in Lasnik 1995, 1999, Kennedy and Merchant 2000, and Merchant 2001.

This explanation extends as well to the data in (5)-(8) above; as we saw there, VPellipsis must target the highest VP. The deletion of a lower VP does not suffice to rescue the structure. ${ }^{6}$ Under the proposed analysis, this is the expected result, assuming as before that the wh-movement targets (at least) the highest VP. ${ }^{7}$ In (8a), repeated here, for example, the deletion of the VP headed by awarded does not remove the intermediate trace $t_{1}{ }^{\prime}$ adjoined to the VP headed by been from the PF structure submitted to the PF well-formedness requirements - as such, $t_{1}{ }^{\prime}$ remains at $\mathrm{PF}$ and violates the $\mathrm{ECP}_{\mathrm{PF}}$.

(21) a. *Abby has been awarded more accolades than has her father been.

b. ... than [CP $O p_{1}$ has [IP her father $t_{\text {has }}\left[\mathrm{VP} t_{1}{ }^{\prime}\left[\mathrm{VP}\right.\right.$ been fvparded $\left.\left.\left.\left.\left.t_{s u} t_{1}\right\}\right]\right]\right]\right]$

Let us now reconsider the case of SAI in matrix wh-questions, where VP-ellipsis is not required, such as in (22), repeated from (10b) above.

How many instruments can Abby play?

\footnotetext{
${ }^{6}$ This fact shows that simply stating a type-hierarchy co-occurrence restriction like $[\{\mathrm{SAI}\} \cap\{$ comparative whmovement $\} \cap\{$ non-VP-ellipsis $\}=\varnothing$ ], as considered at the beginning of this paper for Construction Grammar or some versions of HPSG, is too facile: somehow, the VP-ellipsis must also be restricted to occurring in a certain position. I am unsure whether such additional requirements pose a difficulty for construction-sensitive theories as currently formulated.

${ }^{7}$ Whether every VP in stacked VP structures must be targeted by wh-movement cannot be decided on the basis of the SAI facts alone: putative intermediate traces adjoined to lower VPs would satisfy the ECP $\mathrm{PF}_{\mathrm{PF}}$ in any case. See section 3.3 below for more discussion.
} 
This has the structure given in (23).

$$
\left[\mathrm{CP} \text { How many instruments }{ }_{1} \text { can }\left[\mathrm{IP} \text { Abby } t_{c a n}\left[\mathrm{VP} t_{1}{ }^{\prime}\left[\mathrm{VP} t_{S U} \text { play } t_{1}\right]\right]\right]\right]
$$

As in (17) above, $t_{1}{ }^{\prime}$ does not satisfy clause (i) of the $\mathrm{ECP}_{\mathrm{PF}}$. However, unlike in (17), $t_{1}{ }^{\prime}$ here satisfies clause (ii): the operator How many instruments is PF-visible, and PFantecedent-governs $t_{1}{ }^{\prime}$. Because of this, there is no similar requirement for VP-ellipsis in matrix wh-questions. ${ }^{8}$

At this point, it is important to examine the generality of the analysis presented thus far. While it is successful in handling for an otherwise puzzling and until now unaccounted-for generalization, one may wonder whether it has undesired consequences in domains other than the two examined so far. In particular, it makes the claim that there will be no instance of whmovement out of VP co-occurring with I-to-C movement in which the operator is not PFvisible (in traditional terms, which involves an empty operator). This claim is fairly simple to check, since the environments in which I-to-C movement in English occur are quite limited, which we can consider in two groups.

The first group consists of yes-no questions (24), literary counterfactuals and concessives (25), non-wh-exclamatives (26), and imperatives and hortatives (27).

(24) a. Can she play the piano?

b. Does he know many languages?

(25) a. Had he been on time, we might have made it.

b. Be it ever so humble, there's no place like home.

(26) a. Man, can she play the piano!

b. Am I ever glad to see you!

a. Don't everybody get up at once!

b. May he be a joy to you forever!

These various constructions have in common that there is no overt operator in specCP, and indeed no reason to assume that there has been wh-movement out of the VP at all (though it is sometimes argued that there is some kind of null operator present in specCP for various reasons, this operator is not usually assumed to originate within the clause; see McCloskey 1991:295, Potsdam 1996, and Bennis 1998). These constructions are thus irrelevant to our present concerns.

The second group consists of affective inversion structures (28), and no sooner- (29a), little- (29b), so- (30), and as-constructions (31).

\footnotetext{
${ }^{8}$ Likewise for the trace of the A-moved subject, if the $\mathrm{ECP}_{\mathrm{PF}}$ is generalized to A-traces as well, a possible extension outside the scope of this paper; because the subject is overt, it will satisfy clause (ii) of the $\mathrm{ECP}_{\mathrm{PF}}$. In general, I do not consider subjects here for this reason; wh-moved subjects of comparatives (such as More people can sing than can play the piano) will not be relevant in any case, since in these cases, no SAI is found (see Aoun et al. 1987:567-568, Rizzi 1990:40-41, and Grimshaw 1997 for various explanations of this fact).
} 
(28) Rarely have I ever been so surprised.

(29) a. No sooner had he arrived than it started to rain.

b. $\quad$ Little did he suspect that he had already been betrayed.

Abby can swim a mile, and so can Ben.

Abby got the Nobel Prize, as did her father.

In these cases, some element does precede the moved auxiliary in $\mathrm{C}^{0}$. For affective inversion structures (see Liberman 1974), it has been argued in Haegeman and Zanuttini 1991 that the extracted operator (rarely in (28)) is in specNegP, but the exact location of this specifier and its head (into which $\mathrm{I}^{0}$ moves) does not matter: in either case, since the operator is overt, the $\mathrm{ECP}_{\mathrm{PF}}$ will be satisfied by clause (ii) of (12). Similar remarks apply to (29) and (30), though it is even less clear that any extraction has occurred (though VP-ellipsis may be highly preferred with so, it apparently does not have the same categorical status that the comparative examples above do; see Chomsky and Lasnik 1993 and Quirk et al. 1985:882 for examples of so with SAI without VP-ellipsis ${ }^{9}$ ).

This leaves the case of as. This case bears the strongest resemblance to the comparative data considered above, since VP-ellipsis is required as well (compare (31) with *Abby got the Nobel Prize, as did her father get the Nobel Prize). This state of affairs can be accounted for if the as-construction involves some kind of extraction of an operator to specCP, an assumption strongly supported by island-sensitivity and other evidence (see Postal 1998 and Potts 2000). In particular, it supports the idea that as is not itself the extractee (since in that case, it would be an overt operator, and should not require VP-ellipsis with SAI), but rather that as is a head that co-occurs with a null operator (as with the equative as in Abby speaks as many languages as does her father (*speak) etc.). ${ }^{10}$ The intermediate trace of this null operator, then, will be subject to the $\mathrm{ECP}_{\mathrm{PF}}$ as above, with the expected results.

Thus it appears that the present analysis achieves sufficient generality, applying equally well to other cases in which SAI occurs. Similarly, the vast majority of constructions in which wh-movement takes place (including relative clauses, clefts, pseudoclefts, 'topicalizations', free relatives, and embedded wh-questions) will not be relevant to

\footnotetext{
${ }^{9}$ As E. Potsdam reminds me, for many speakers, VP-ellipsis is obligatory with $s o$. For such speakers, we must assume that so is like as in selecting a CP whose specifier is filled by an empty operator, presumably an extracted VP (see Potts 2000 in particular for justification that such so-clauses involve extraction of a VPoperator). For speakers who share the judgments of Chomsky, Lasnik, and Quirk et al., so is presumably in specCP. Another possibility, suggested to me by S. Winkler, is that the construction with so simply doesn't involve ellipsis at all, so being itself the (moved) predicate, as in López 1995, and hence irrelevant here.

${ }^{10}$ This is supported as well by that fact that as can be used as a complementizer in some dialects, equivalent to that in standard English (occurring in selected complement clauses and in headed relative clauses, for example). The data in (i) and (ii) illustrate these uses of as respectively, taken from the lower class British speech of the characters of Dorothy Sayers:

(i) a. She was quite ready to believe as she done wrong. [D. Sayers, Unnatural Death, 1927, p. 109]

b. I don't know as I ought to tell you. [loc. cit.]

(ii) This is Mr. Murbles, as put in that unfortunit advertisement, as I truly believes was the beginnin' of it all. [op. cit. p. 104]
} 
distinguishing the effects of the $\mathrm{ECP}_{\mathrm{PF}}$ from those of the traditional ECP applying only at $\mathrm{LF}$, since in none of these cases do we find concomitant I-to-C movement. ${ }^{11}$

\section{$3 \quad$ Further considerations}

At this point, we have seen that the $\mathrm{ECP}_{\mathrm{PF}}$ can successfully account for the generalization given in (1), and have been led to an interesting view of the kinds of constraints that can operate at the PF interface, an issue that I return to in the Conclusion below. Before concluding however, three further points are worth briefly exploring: comparatives with overt operators, pseudogapping, and V-to-I movement, which will be taken up in the following three sections in turn.

\subsection{Comparatives with PF-visible operators}

The first point is an intriguing prediction of sorts that the analysis makes, which as it turns out is unfortunately difficult to test for independent reasons. We have seen that in standard English comparatives, in which the operator in specCP is nonovert, SAI is impossible without concomitant VP-ellipsis. But the account given leads us to expect that if the operator were overt, SAI should be possible even without VP-ellipsis. There are varieties of American English that permit an overt operator, namely the invariant what, in some comparatives (see Hankamer 1973). Although it is somewhat difficult to find speakers for whom judgments involving such comparatives are absolutely secure, due to prescriptive prohibitions against the overt operator, it appears that the kind of example we would expect to find are nevertheless ungrammatical:
a. $\quad *$ Abby can sing more songs than what can her dad sing.
b. *Abby knows more languages than what does her father know.

Despite first, worrisome appearances, these data in fact shed no light on the account given above, because SAI in comparatives is unacceptable in these varieties even with VP-ellipsis:
a. *Abby can sing more songs than what can her dad.
b. $\quad *$ Abby knows more languages than what does her father.

Thus it is clear that the source of the judgments in (32) lies elsewhere, and does not have to do with the $\mathrm{ECP}_{\mathrm{PF}}$. One possibility is that the examples in both (32) and (33) are judged unacceptable because they involve a fatal register clash: while use of the overt operator what in comparatives is colloquial and belongs to a very low, informal spoken register, the use of SAI in comparatives belongs to an extremely high, formal register of English. In other words, no single register's grammar can produce these two in a single sentence (barring intentional

\footnotetext{
${ }^{11} \mathrm{We}$ are of course left with the intriguing residual question of why the observed difference should exist between the ability of overt (PF-visible) and empty (not PF-visible) operators to license intermediate traces. Clearly this fact should find its place in a general theory of how these kinds of operators differ, presumably relating to more general considerations of recoverability and identification; see in particular Grosu 1994 for extensive discussion.
} 
register mixing). ${ }^{12}$ Another possibility, suggested to me by E. Potsdam, is that the syntax of the what-clauses in (32) and (33) is essentially that of (free) relatives, an analysis made plausible by other evidence as well (animacy restrictions, the unrestricted interpretations found in attributive comparatives, etc.); see den Besten 1978 for extensive discussion. If this is the case, then we do not expect to find SAI in any case, since SAI is excluded in (free) relatives in general.

\subsection{SAI, VP-ellipsis, and pseudogapping}

The second point worth exploring is the interaction of the present cases with pseudogapping. Pseudogapping as in (34a) is most widely analyzed as consisting of adjunction of a remnant XP to VP followed by VP-ellipsis (see Kuno 1981, Jayaseelan 1990, Kennedy and Merchant 2000, Johnson 2001; see Lasnik 1995 for a related but differing viewpoint), represented in (34b) as left-adjunction for convenience.

a. I eat meat, but I don't seafood.

b. $\quad . .$. I don't [ $\mathrm{vP}$ seafood $\left.\mathrm{fvP}_{\mathrm{v}-t_{S U}} \mathrm{t}_{O B} \mathrm{f}\right]$

Pseudogapping is compatible with SAI, as the examples in (35) show (from Sag 1976a and Kempson et al. 1999:282 fn 43, respectively), though as Levin 1986 points out, such examples are somewhat marked.

a. A: Hey! I've never seen you on campus before. B: Nor have I you!

b. John didn't give a nickel to Mary, nor did I a dime to Sue.

Pseudogapping also occurs in comparative clauses, as in (36); in fact, the best examples of pseudogapping are precisely in comparatives, as Levin 1986 observes.

Abby plays the flute better than her father does the trumpet.

Given Levin's observation, it is particularly surprising that pseudogapping with SAI in comparatives is impossible, as (37) shows. ${ }^{13}$

\footnotetext{
${ }^{12}$ A parallel to this situation might be found with pied-piping of prepositions and the use of the archaic form whom: many speakers reject examples with pied-piping of who, since the latter, bare, form belongs to a more colloquial register that prohibits pied-piping in favor of preposition stranding; cf. ®*With who did he speak? (where ${ }^{\circledR} *$ indicates a register clash) vs. the prescriptively correct With whom did he speak?. See Lasnik and Sobin 2000 for discussion.

${ }^{13}$ Levin also observes that the level of acceptability of examples of pseudogapping deteriorates with unlike subjects (as with SAI); this fact alone may account for some of the unacceptability of the examples in this section. I am operating on the assumption that this fact itself is in need of an explanation, and in any case, Levin's observations are more of a general nature, and not meant as an absolute measure - she herself notes several examples where these conditions are not met, but pseudogapping remains possible. The pseudogapping examples in this section use unlike subjects because SAI in comparatives prohibits like subjects in any case: $A_{b b y_{1}}$ is taller now than was $\left\{\right.$ her father / * she $\left.{ }_{1}\right\}$ last year vs. Abby $y_{1}$ is taller now than $\left\{\right.$ her father / she $\left.{ }_{1}\right\}$ was last year (see also Potts 2000:11-12 for discussion with respect to as as well; Potts points out that inversion creates an anti-pronominal context in the sense of Postal 1998, following the observation made in Quirk et al. 1985:1382).
} 
*Abby plays the flute better than does her father the trumpet.

We can make sense of this fact if wh-extraction out of a VP must target the highest VP-segment. In this case, an example like (37) will have the structure in (38). In (38), VPellipsis has deleted the VP segment below the adjoined remnant the trumpet, leaving the intermediate trace $t_{1}{ }^{\prime}$ intact at $\mathrm{PF}$, where it violates the $\mathrm{ECP}_{\mathrm{PF}}$

$$
\left.\ldots \text { than } O p_{1} \text { does her father } t_{\text {does }}\left[\mathrm{vP} t_{1}{ }^{\prime}\left[\mathrm{VP} \text { the trumpet fvP-ts } t_{S U} \text { play } t_{O b} t_{1}\right\}\right]\right]
$$

Crucially, a derivation in which wh-extraction targets VP first, followed by remnant adjunction, followed by VP-ellipsis must be ruled out, as this would lead to the PF representation in (39), where $t_{1}{ }^{\prime}$ can be deleted along with the intermediate VP segment (see Sag 1976b, Merchant 2000 for discussion of VP segments as targets of deletion).

$$
\text { ... than } O p_{1} \text { does her father } t_{d o e s}\left[\mathrm{vP} \text { the trumpet } \mathrm{fvP}_{\mathrm{VP}} \boldsymbol{t}_{1}{ }^{\prime} \mathrm{fvP}_{\mathrm{vP}} t_{S U} \mathrm{play} t_{O B} t_{1} \mathrm{H}\right]
$$

There is in fact independent indication that such a restriction on the ordering of multiple A'-movement is in force (see Fox 1999), which presumably should be derived (see Chomsky 2001's notion of 'phases' and extractions from them). If (38) represents the only licit derivation, then, the absence of pseudogapping with SAI in comparatives also falls out from the analysis proposed above.

Crucially, this restriction holds only for multiple (A'-) extractions out of VP, utilizing adjunction to VP as a landing site, and does not hold of base-generated VP-adjuncts such as adverbials. As Potts 2000 points out, the restriction regarding pseudogapping does not extend to what are presumably VP adjuncts:

(40) Klaus would be happier in the north than would Chuck in the south. (Potts 2000:15 (61a))

Fully exploring the contrast between examples like (40) and that in (37) would take us beyond the scope of the present inquiry, but several lines of analysis are open to us. First, one might wonder whether in these case the attested adverbials are in fact adjoined to VP, and not to some higher projection (I', IP); determining the exact adjunction site of right-adjoined adverbials is notoriously difficult, and is complicated by the fact that they can undergo rightward movement as well (in this regard it is important to note that the remnant of pseudogapping must precede such adverbials: cf. I'd build a house in the north before I would a cabin in the south vs. *I'd build a house in the north before I would in the south a cabin; see Sobin 1981 for contrasting data from gapping, for instance). A second possibility, assuming in the south in (40) is in fact right-adjoined to VP, would be to explore whether the directionality of adjunction might make a difference: if it could be shown that the remnant of pseudogapping, presumably like wh-movement, left-adjoins to VP, one might pursue an account of the differences between such remnants and adjuncts based on this fact. Third, one might claim simply that adverbial elements don't factor in the computation at PF in a relevant way, as proposed for other reasons by Bobaljik 1995; here, we might assume that VP-ellipsis 
can target the highest VP segment, eliminating the illicit trace in the way discussed, but not necessarily delete a right-adjoined adverbial (following in essence Sag's 1976b proposal).

Finally, one might claim, if the attested restriction on extraction ordering is to be derived from phase-edge effects following Chomsky 2001, that merger of adjuncts at the VP doesn't affect the computation of the edge, allowing a moved element below the merged adjunct to still qualify as at the phase-edge (allowing further extraction), whereas multiple movements to the VP edge (as in the pseudogapping cases) does affect this computation. Essentially, we would claim that only one moved element, the highest one, counts as being at the phase-edge (this must be related in some manner to the differing features driving the movements involved, since multiple wh-extraction is permitted, of course; I leave open the many questions that arise). If this latter line of analysis is on the right track, the following picture emerges: when both the comparative operator and a pseudogapped remnant are moved, the resulting VP structure is that in (41a), where underlining indicates elements at the edge of the VP-phase - because the wh-operator must be extracted further, to specCP, it must be on the edge of the phase, as discussed above. But Merge targeting a VP that has a comparative operator adjoined to it by previous movement, adjoining a VP adjunct (represented as left-adjoined in (41b) for ease of comparison with (41a)), does not alter the status of the moved XP at the edge, resulting in either an expanded edge, as indicated with underlining in $(41 \mathrm{~b})$, or perhaps simply not affecting the edge computation at all. ${ }^{14}$

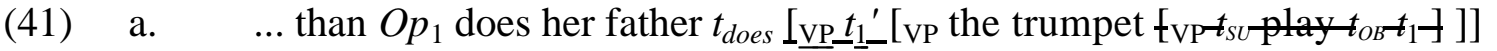

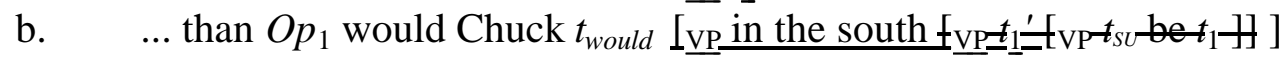

If this analysis is on the right track, the contrast between base-generated adjuncts and remnants of pseudogapping for blocking further wh-movement of the comparative operator falls out from the independent computation of phase-edges. Because the intermediate landing site of the comparative operator in (41b) is below the adjunct, but still on the edge, the operator can be extracted to specCP, and the VP to which $t_{1}{ }^{\prime}$ is adjoined can be deleted as indicated, saving the structure from an $\mathrm{ECP}_{\mathrm{PF}}$ violation as in (20) above.

It is thus clear that there are various analytical options available to us to account for the contrast between (37) and (40), though deciding between them should ideally be done on the basis of evidence unrelated to the data from comparatives; since doing so is not material to my present purposes, such an expanded investigation can safely await further research.

Pseudogapping raises another interesting issue, however. In such examples, the object of comparison can be an attributive adjective originating in the remnant of pseudogapping, as in (42a). Following Kennedy and Merchant 2000, I assume that such examples involve movement of the comparative operator (here, a DegP) out of the DP a concerto, followed by movement of a concerto to VP, followed by VP-ellipsis (here obligatory, for reasons discussed in detail in Kennedy and Merchant 2000); this derivation results in the structure in (42b).

\footnotetext{
${ }^{14}$ Such a conclusion is needed independently to allow wh-extraction in the presence of VP-adjuncts in any case (or VP-internal subjects, for that matter).
} 
a. Abby played a longer sonata than her father did a concerto.

b. $\quad \ldots$ than $O p_{2}$ her father did [VP $t_{2}{ }^{\prime \prime}\left[\mathrm{VP}\left[\mathrm{a} t_{2} \text { concerto }\right]_{1}\right.$ fvP $_{\mathrm{VPy}} \mathrm{FFP}_{2} t_{2}{ }_{\mathrm{F}} \mathrm{F}^{0} t_{1}$ 册 ]]

Given the analysis developed so far, we expect that in such cases, SAI will be impossible, since $t_{2} "$ in (42b) will violate the $\mathrm{ECP}_{\mathrm{PF}}$. This prediction is correct:

*Abby played a longer sonata than did her father a concerto.

Further, it is interesting to note that the remnant of pseudogapping can itself be the object of comparison, in nominal amount comparatives such as (44) (here, VP-ellipsis is only optional, as noted in Kennedy and Merchant 2000:101 fn 10).

Abby can play more sonatas than her father can concertos.

In these cases, as with attributive comparatives, SAI and pseudogapping are incompatible:

*Abby can play more sonatas than can her father concertos.

This follows under the present account if such nominal subdeletions involve movement of an empty operator to specCP, as is usually assumed (see Chomsky 1977, Kayne 1981:98-99, Grimshaw 1987, Corver 1993, and Izvorksi 1995), an analysis suggested especially by the fact that nominal subdeletions are sensitive to the availability in a given language of preposition-stranding (see Milner 1978, Kayne 1981). ${ }^{15}$

Finally, note that SAI is not found in predicative adjectival subdeletion structures either:

*Abby is taller than is her father short.

This fact is again expected under the present analysis if these structures involve movement of an empty operator from a VP-adjoined position (as mooted by Izvorski 1995 in particular) or a VP-internal one (a possibility supported by the fact that attributive adjectival subdeletion is impossible in general, reducible to a Left Branch effect if the operator moves from the DegP inside the DP).

\section{$3.3 \quad$ V-to-I movement}

The last point worth examining here is the interaction of $\mathrm{V}$-to-I movement with the $\mathrm{ECP}_{\mathrm{PF}}$, with a particular view to seeing what light the present analysis can shed on the nature of this movement, especially vis-à-vis I-to-C movement. The question that arises is whether V-to-I movement has the same effect on the licensing of wh-traces as I-to-C movement has. The answer is no, as we will see immediately. This fact raises a substantive issue: is this nonparallel behavior of head movement to be traced somehow to the differing nature of V-to-I vs.

\footnotetext{
${ }^{15}$ I will have to leave it open how these facts could be reconciled with the account of subdeletion proposed in Kennedy 2002.
} 
I-to-C movement, or does it derive from independent properties of the resulting structures? This in turn raises an analytical issue: is it possible to reformulate the definitions given above to retain the advantages of the account constructed thus far without faltering on V-to-I movement, and if so, what is the best way to do this? The evidence bearing on these questions is at times quite subtle, and to a great extent dependent on considerations of a more global nature than I have been concerned with here. Before tackling these questions, let me lay out what the relevant data will be.

V-to-I movement occurs in the most widely spoken varieties of English only with inflected forms of the verb be and the auxiliary have (modals being base-generated in $\mathrm{I}^{0}$, and other auxiliaries being quite marginal). There are two kinds of cases that will be of interest here: first, where the operator involved originates as the complement to be, as in (47), and second, where the operator extracts from a series of VPs selected by a verb that raises into $\mathrm{I}^{0}$, as in (48).

(47) a. I didn't know how fast she was.

b. He's not the man he was.

(48) a. They asked what instruments she had been playing.

b. Abby has been playing the same instruments her father has been.

c. The Nobel is the only prize (which) Abby hasn't been awarded.

For the first set of cases, the relevant portion of the structure is given in (49).

a. $\quad \ldots$ [CP how fast ${ }_{1}\left[\mathrm{IP}\right.$ she was $\left.\left.\left[\mathrm{VP}_{\mathrm{VP}} t_{1}{ }^{\prime}\left[{ }_{\mathrm{VP}} t_{\text {was }} t_{1}\right]\right]\right]\right]$

b. $\quad \ldots\left[{ }_{\mathrm{CP}} O p_{2}\left[\mathrm{IP}\right.\right.$ he was [ $\left.\left.\left.{ }_{\mathrm{VP}} t_{2}{ }^{\prime}\left[\mathrm{VP} t_{\text {was }} t_{2}\right]\right]\right]\right]$

The problem that emerges here is how the lower traces ( $t_{1}$ and $t_{2}$, respectively) satisfy the $\mathrm{ECP}_{\mathrm{PF}}$ (The higher, VP-adjoined traces will be licensed by clause (i) of the $\mathrm{ECP}_{\mathrm{PF}}$ as we have seen.) In (49a), $t_{1}$ does not satisfy clause (i) of the $\mathrm{ECP}_{\mathrm{PF}}$ as formulated in (12) because its head-governor, the trace of was, is not PF-active as required for PF-head-government in (13); was in $\mathrm{I}^{0}$ itself is prevented from being the head-governor by Relativized Minimality (necessarily so, since if all moved heads could govern through their traces, the I-to-C movement effects would remain a mystery). This leaves the possibility that the $\mathrm{ECP}_{\mathrm{PF}}$ is satisfied via PF-antecedent-government. But this possibility also fails: the closest antecedentgovernor for $t_{1}$ is $t_{1}{ }^{\prime}$, by Relativized Minimality, and this trace is not PF-visible as required for PF-antecedent-government. So $t_{1}$ in (49a) fails to be either PF-head-governed or PFantecedent-governed, and the structure should violate the $\mathrm{ECP}_{\mathrm{PF}}$, a conclusion in conflict with its status as perfectly grammatical. Precisely the same reasoning applies to (49b).

The examples in (48) present a different prima facie difficulty, if we assume that whmovement proceeds cyclically by adjunction to every VP in stacked VP structures. If this is so, these examples will have the structures in (50), where only the traces of interest are given.

(50) a. $\quad \ldots$ [CP what instruments ${ }_{1}$ [IP $_{\mathrm{CP}}$ she had [ $\mathrm{VP}_{\mathrm{VP}} t_{1}{ }^{\prime \prime}{ }_{\mathrm{VP}} t_{\text {had }}\left[{ }_{\mathrm{VP}} t_{1}{ }^{\prime}\right.$ [VP $_{\mathrm{VP}}$ been playing $t_{1}$

]]]]]

b. $\quad \ldots\left[\mathrm{CP} O p_{2}\left[\mathrm{IP}\right.\right.$ her father has [ ${ }_{\mathrm{VP}} t_{2}{ }^{\prime \prime}\left[\mathrm{VP}_{\mathrm{VP}} t_{\text {has }}\left[\mathrm{VP} t_{2}{ }^{\prime}\left[\mathrm{VP}\right.\right.\right.$ been fvp playing $\left.\left.\left.\left.\left.t_{2} \mathrm{f}\right]\right]\right]\right]\right]$

c. $\quad \ldots\left[{ }_{\mathrm{CP}}\left(\mathrm{which}_{3}\right)\left[\mathrm{IP}_{\mathrm{P}}\right.\right.$ she hasn't $\left[\mathrm{VP}_{3} t^{\prime \prime}{ }_{\mathrm{VP}} t_{\text {has }}\left[\mathrm{vP} t_{3}{ }^{\prime}\left[\mathrm{vP}\right.\right.\right.$ been [vp awarded $\left.\left.\left.\left.\left.\left.t_{3}\right]\right]\right]\right]\right]\right]$ 
The difficulty comes from the trace which is adjoined to the VP complement of the base position of the raised verb: $t_{1}{ }^{\prime}, t_{2}{ }^{\prime}$, and $t_{3}{ }^{\prime}$ in (50a), (b), and (c), respectively. Here we face a similar situation to the one just described for complements of moved be: $t_{1}{ }^{\prime}$ in (50a) is neither PF-antecedent-governed (since the closest antecedent-governor is $t_{1}{ }^{\prime \prime}$, which is not PF-visible) nor PF-head-governed (since $t_{\text {had }}$ is not PF-active). Of course, this kind of example only poses a difficulty if wh-extraction proceeds via adjunction to every VP: if, on the other hand, extraction proceeds only via adjunction to the highest VP in such stacked VP structures, nothing more need be said, since a trace adjoined to this VP is PF-head-governed by the raised verb in $\mathrm{I}^{0}$. Although it has not been settled in the literature whether such cyclic adjunction is necessary, I will proceed on the assumption that under the system generally used here, extraction will result in such intermediate adjoined traces.

I take it that the difficulty in these two kinds of examples can be traced back to the same source and that, since the difficulty cuts across the distinction between overt and null operators, this source is to be located in the nature of PF-head-government. In some fashion, and counter the naive expectation raised by the case of I-to-C movement, the structures in (49) and (50) manage to satisfy the $\mathrm{ECP}_{\mathrm{PF}}$ despite the attested verb movement: for some reason, V-to-I movement does not have the effect of disrupting PF-head-government of traces that would have been PF-head-governed from the original position of the moved $\mathrm{V}$. The question that must be answered, then, is why this should be so.

There are two possible answers to this question. The first takes as its starting point the idea that the traces of the moved verbs are PF-head-governors despite that fact that they are not, under our current definitions, $\mathrm{PF}$-active; in other words, why is it that a trace of a verb $\left(t_{V}\right)$ raised to $\mathrm{I}^{0}$ qualifies as a PF-head-governor, but the trace of $\mathrm{I}\left(t_{I}\right)$ raised to $\mathrm{C}^{0}$ does not?

Posing the question this way leads us to search for a principled distinction between the kinds of movement involved, considering especially properties of the moved elements and the positions they are moved from. Indeed, it is not difficult to find discussions of the quite different nature of the inherent governing properties of V vs. I: much of the literature on the nature of (especially proper) head-government has stressed exactly the defective nature of $\mathrm{I}^{0}$, in contrast to the more durable ability of $\mathrm{V}^{0}$ to properly head-govern, accounting especially for subject-object extraction asymmetries in these terms. Following this line of thought, we could revise the definition of PF-active in (14) to be sensitive to these differences: in terms of the theory of Chomsky 1986, for example, where V L-marks its complement but I does not (Chomsky 1986:79), we can redefine PF-active as follows:

A link $\alpha_{i}$ in a chain $\left\langle\alpha_{1}, \ldots, \alpha_{n}>\right.$ is PF-active iff $\alpha_{i}$ is the link at which lexical insertion or L-marking occurs.

Under this definition, the lowest position in a chain of verb movement is always a PF-headgovernor, since it is from this position $\left(\alpha_{n}\right)$ that L-marking proceeds (i.e., a verb V L-marks its complement when $\mathrm{V}$ is in the position $\alpha_{n}$, not in any other, derived, position). Viewed from the perspective of positions in the tree, this kind of solution claims essentially that the position I is defective with respect to PF-head-government, and must be targeted by lexical 
insertion in order to qualify as a PF-head-governor, whereas $\mathrm{V}$ always qualifies as such, regardless of whether it is the position targeted by lexical insertion or not.

This approach bears most similarity to the approach to defining head governors advocated in Chung 1991, who restricts head governors to those heads that either belong to a given set (among which V), or else are phonetically overt (Chung 1991:120). Though the class picked out there is slightly different from the one required here, the similarity is otherwise close: lexical heads are 'prototypical head governors' (Chung 1991:107) whose headgovernment properties are invariant, while more defective functional heads like D must be phonetically overt to qualify as head governors (see also Chung 1998:276-322 for extensive recent discussion). The approach also bears a similarity to the definition of 'PF-visible' advocated in Aoun et al. 1987, who propose that a head H will qualify as a PF-head-governor either if $\mathrm{H}$ is phonetically overt or if $\mathrm{H}$ has acquired an 'index through the application of grammatical processes like a syntactic movement rule...' (Aoun et al. 1987:539). They leave it somewhat open what may count as a qualifying 'grammatical process'; if V-to-I movement, but not I-to-C movement, were posited to pass on an index in their system, the distinction necessary here could be made as well (a distinction that may well be derivable from independent factors, if V-to-I movement occurs in the syntax before Spell-Out, but I-to-C at $\mathrm{PF}){ }^{16}$

Such an analysis, though perfectly adequate and consistent with previous theoretical work, suffers primarily from the need to posit a disjunction in the definition of PF-active; as Rizzi 1990:76-77 points out, disjunctive statements sometimes point to a deficient understanding of the underlying properties at issue, though they may be productive and useful research vehicles nonetheless. This metatheoretical concern is essentially the only objection one could bring to the redefinition of PF-active in terms sensitive either to lexical insertion or L-marking (or its equivalent) in (51).

The second possible answer to the question of why V-to-I and I-to-C movement have the variable effects seen in English explores the possibility of imposing a PF-adjacency requirement on PF-head-government, as Aoun et al. 1987:573-575 do (cf. also Kayne 1981:98). The simplest way to do this is to alter the definition of PF-head-government in (13) above by replacing clause (i.c) (the Relativized Minimality requirement) by a clause requiring that $\alpha$ be $P F$-adjacent to $\beta$. Two elements can then be defined as PF-adjacent iff no PF-visible head or specifier separates them. ${ }^{17}$

This additional requirement draws the desired distinctions, as a brief consideration of the relevant cases shows. In the case of I-to-C movement, the subject will intervene between I in $\mathrm{C}$ and the VP-adjoined wh-trace, blocking PF-adjacency, with the results of the analysis

\footnotetext{
${ }^{16}$ In fact, Aoun et al. are somewhat unclear on whether head movement leaves an indexed trace: on p. 539 they assume that 'rules moving ... nonphrasal categories do not leave ... indices', while on p. 546, they claim that 'the trace of a moved verb ... is indexed', in order to account for V2 effects in Dutch; they further point out that the literature on the question is equivocal, citing Torrego 1984 and Bouchard 1985 for conflicting claims regarding the ability of moved verbs to count as governors for the purposes of the ECP.

${ }^{17}$ For purposes of adjacency, adjoined elements such as adverbs do not count, either for the reasons posited by Bobaljik 1995, or, at least for the cases in (48), simply because the option of adjoining the adverbs below the wh-trace has been taken. In this regard, it is also interesting to note that negation does not count, as (48c) above indicates (while in the computation relevant for $d o$-support, negation destroys adjacency; I conclude from this fact that 'affix-hopping' is not dependent on PF-head-government as defined here).
} 
unaffected. But in the case of V-to-I movement, the raised V remains PF-adjacent to the trace in question.

In the first set of cases, where the lowest trace of wh-movement is the complement position of the raised verb, the redefinition has the following effect. In (49a), for example, (the relevant part of whose structure is ...was $\left.\left[{ }_{\mathrm{vP}} t_{1}{ }^{\prime}\left[{ }_{\mathrm{vP}} t_{s u} t_{\text {was }} t_{1}\right]\right]\right) t_{1}$ and $t_{1}{ }^{\prime}$ are both PF-adjacent to the raised verb was in $\mathrm{I}^{0}: t_{1}{ }^{\prime}$ because nothing intervenes between it and $\mathrm{I}^{0}$, and $t_{1}$ because neither the trace of the raised subject in specVP nor the trace of was itself counts as an intervener, since they are not PF-visible.

In the second set of cases, the problematic trace is adjoined to the VP complement to the origin site of the raised verb in $\mathrm{I}^{0}$. Consider for example (50a), the relevant part of whose structure is the following: ...had [ ${ }_{\mathrm{vP}} t_{1}{ }^{\prime \prime}{ }_{\mathrm{V}} t_{\text {had }}$ [vP $t_{1}{ }^{\prime}\left[\ldots\right.$. In this structure, $t_{1}{ }^{\prime \prime}$ is PF-headgoverned as before, since had in $\mathrm{I}^{0}$ is PF-adjacent to it. The intermediate trace that concerned us before, $t_{1}{ }^{\prime}$, is now PF-head-governed by had in $\mathrm{I}^{0}$ as well, since $t_{1}{ }^{\prime}$ is PF-adjacent to had the intervening trace $t_{\text {had }}$ does not block PF-adjacency because it is not PF-visible (and likewise for the possible trace of the subject in specVP, if subjects must move through all intervening VP-specifiers).

Again, we see that it is possible to construct an adequate account of the facts by appropriately redefining PF-head-government, in this case to include a PF-adjacency condition. And once again, primarily metatheoretical concerns might trouble us on this point: adjacency conditions are usually proposed with a modicum of embarrassment, since in general it seems that adjacency is something we would like to derive from other requirements, and not stipulate in the syntax. But note that it is not debated that adjacency plays an important role in grammar, most prominently in numerous phonological effects (see Walker 1998 for discussion). Any definition making use of adjacency, then, might be expected to be active on the PF side of the grammar, precisely the case here. Thus while Stowell's 1981 analysis of adjacency effects on Case-assignment are suspect if Case is not merely a PF phenomenon (cf. also McCloskey's 1991 analysis of Case-assignment under government from $\mathrm{I}^{0}$ in Irish), his analysis of the conditions on that-deletion continue to play a role in current theorizing (Fox 2000), since it seems that this deletion, like many others, occurs on the PF side of the derivation. $^{18}$

18 A more substantive objection (besides the general problems inherent in Bobaljik's stipulation, also required here, that adjuncts do not count for purposes of adjacency) might be raised if one wished to extend the analysis directly to languages other than English. In particular, a question arises concerning the application of the analysis to languages that have generalized V-to-I raising as well as null operators, such as Irish, Greek, French, Spanish, Hebrew, Arabic, colloquial Russian, and many others; in these languages, the facts are much the same as for their more limited English counterparts: V-to-I raising does not interfere with wh-movement of null operator complements of V. For example, the Irish relative clause in (i) shows both types of movements (McCloskey 1979:6 (5)):

(i) an scríbhneoir [CP $O p_{1} \quad \mathrm{a}^{\mathrm{L}} \quad$ [IP $\operatorname{mholann}_{V}\left[\mathrm{VP} t_{1}{ }^{\prime}\left[\mathrm{vP}\right.\right.$ na mic léinn $\left.\left.\left.t_{V} t_{1}\right]\right]\right]$. the writer $\quad C_{\text {trace }}$ praise the students

'the writer whom the students praise'

In such a case, the adjacency requirement as formulated in the text will not account for the satisfication of the $\mathrm{ECP}_{\mathrm{PF}}$, since the subject na mic léinn intervenes between the raised verb mholann and $t_{1}$. We can either take this fact to indicate that some cross-linguistic variability must be countenanced in this domain (cf. Chung 1991's Chamorro-particular definition of 'strong' governors), or simply that the approach using the redefinition of PFactive in (51) is to be preferred to the PF-adjacency approach under consideration. Since the goal of this paper is restricted to analyzing the English facts, I will leave the choice between these options open. (Note finally that the I-to-C movement in V2 languages such as Dutch and German won't be relevant, since V2 and wh- 
In sum, the facts of V-to-I movement are compatible with the present analysis under two different and equally viable minor redefinitions of PF-head-government. The first builds upon a posited difference between V-to-I and I-to-C movement related to the lexical nature of the base position $\mathrm{V}$, while the second capitalizes on the fact that subjects in English appear between I and $\mathrm{C}$ and disrupt PF-adjacency. In either case, we have a workable adaptation of the above analysis of the fact that $\mathrm{I}^{0}$ moving into $\mathrm{C}^{0}$ causes a disruption of PF-headgovernment in the manner we have seen, while verbs moving into $\mathrm{I}^{0}$ have the ability to satisfy the $\mathrm{ECP}_{\mathrm{PF}}$ via, or in spite of, their traces.

\section{Conclusion}

The analysis presented here rests on three elements: first, that wh-movement of the comparative operator proceeds via adjunction to the VP sister of $\mathrm{I}^{0}$; second, that the resulting intermediate trace is subject to an ECP operating at the PF interface; and third, that I-to-C movement destroys the possibility that this ECP can be satisfied by head-government by $\mathrm{I}^{0}$. These three elements have the result that in comparatives, where the extracted operator is nonovert, structures in which I-to-C movement has applied will always be accompanied by VP-ellipsis. The result is an internally coherent analysis of the surprising and subtle generalization that opened this paper, an analysis which furthermore is compatible with all other instances of subject-auxiliary inversion in English, and which does not rely on construction-specific statements or restrictions.

The theoretical import of the present analysis is not merely that there must be a licensing condition on traces that applies at PF, and that this condition must have the disjunctive character of Chomsky's 1981, 1986 ECP (not the conjunctive character of Rizzi 1990, for example), but simpliciter that there must be such a licensing condition at all. This is a conclusion some recent work has attempted to avoid, instead building the traditional representational well-formedness conditions such as the ECP into the well-formedness conditions on the movement operation itself. If the analysis presented here is correct however, such efforts cannot suffice to account for the full range of data a static $\mathrm{ECP}_{\mathrm{PF}}$ can: presumably no derivational version of the ECP can be devised that would have the ability to look ahead to the output of PF deletion, and license the intermediate traces in question just in case such a later PF operation were to apply. Since it is exactly VP deletion that rescues otherwise ill-formed structures, and since this deletion happens in the mapping from SpellOut to PF, no derivational constraint applying (stepwise or otherwise) before Spell-Out will be able to take this deletion into account. A static well-formedness condition such as the $\mathrm{ECP}_{\mathrm{PF}}$ pursued here, on the other hand, will apply only after all deletion operations have, at the PF interface itself, and will be sensitive to exactly this kind of information, with the results we have seen.

Indeed, if Chomsky 1995 and others are correct in analyzing I-to-C movement itself as a kind of movement that takes place on the PF side of the derivation (though see Zwart 2001 for important qualifications), then we have no recourse but to look to conditions on that side of the derivation to account for the generalization established here, since it is only in

movement only co-occur in matrix clauses with overt operators, given Reis 2000's convincing re-analysis of the purported cases of embedded V2 as a special kind of parenthetical.) 
structures in which SAI has occurred that such VP-ellipsis is required. Putting these considerations together, we find all the more reason to posit well-formedness constraints such as the $\mathrm{ECP}_{\mathrm{PF}}$ that operate exclusively at the PF interface.

\section{References}

Alexiadou, Artemis and Elena Anagnostopoulou. 1998. Parametrizing AGR: Word order, Vmovement, and EPP-checking. Natural Language and Linguistic Theory 16: 491-539.

Aoun, Joseph, Norbert Hornstein, David Lightfoot, and Amy Weinberg. Two types of locality. Linguistic Inquiry 18: 537-577.

Barbosa, Pilar, Danny Fox, Paul Hagstrom, Martha McGinnis, and David Pesetsky (eds.). 1998. Is the best good enough? MIT Press: Cambridge, Mass.

Bennis, Hans. 1998. Exclamatives! In Renée van Bezooijen and René Kager (eds.), Linguistics in the Netherlands 1998, 27-40. John Benjamins: Amsterdam.

den Besten, Hans. 1978. On the presence and absence of wh-elements in Dutch comparatives. Linguistic Inquiry 9: 641-672

Bobaljik, Jonathan. 1995. Morphosyntax: The syntax of verbal inflection. PhD thesis, MIT.

Bouchard, Denis. 1985. Local relations in 'long distance' wh-constructions. Ms., University of Texas, Austin.

Chomsky, Noam. 1977. On wh-movement. In Peter Culicover, Thomas Wasow, and Adrian Akmajian (eds.), Formal syntax, 71-132. Academic Press: New York.

Chomsky, Noam. 1981. Lectures on government and binding. Foris: Dordrecht.

Chomsky, Noam. 1986. Barriers. MIT Press: Cambridge, Mass.

Chomsky, Noam. 1995. The Minimalist Program. MIT Press: Cambridge, Mass.

Chomsky, Noam. 2001. Derivation by phase. In M. Kenstowicz (ed.), Ken Hale: A life in language, 1-52. MIT Press: Cambridge, Mass.

Chomsky, Noam and Howard Lasnik. 1993. Principles and parameters theory. In Joachim Jacobs, Arnim von Stechow, Wolfgang Sternefeld, and Theo Vennemann (eds.) Syntax: An international handbook of contemporary research, 506-569. De Gruyter: Berlin.

Chung, Sandra. 1991. Functional heads and proper government in Chamorro. Lingua 85: 85-134.

Chung, Sandra. 1998. The design of agreement: Evidence from Chamorro. University of Chicago Press: Chicago, Ill.

Corver, Norbert. 1993. A note on subcomparatives. Linguistic Inquiry 24: 773-781.

Fox, Danny. 1999. Reconstruction, binding theory, and the interpretation of chains. Linguistic Inquiry 30:157-196.

Fox, Danny. 2000. Antecedent-contained deletion and the copy theory of movement. Ms., Harvard University.

Goldberg, Adele. 1995. Constructions: A Construction Grammar approach to argument structure. University of Chicago Press: Chicago.

Goldsmith, John. 1981. Complementizers and root sentences. Linguistic Inquiry 12: 541-574.

Grimshaw, Jane. 1987. Subdeletion. Linguistic Inquiry 18: 659-669.

Grimshaw, Jane. 1997. Projections, heads and optimality. Linguistic Inquiry 28:373-422..

Grosu, Alexander. 1994. Three studies in locality and case. Routledge: London.

Haegeman, Liliane and Raffaella Zanuttini. 1991. Negative heads and the Neg-criterion. The Linguistic Review : 233-251.

Hankamer, Jorge. 1973. Why there are two than's in English. In C. Corum, T.C. Smith-Stark, and A. Weiser (eds.), Papers from the 9th regional meeting of the Chicago Linguistics Society, 179-191. Chicago Linguistics Society: Chicago, Ill.

Halle, Morris and Alec Marantz. 1993. Distributed Morphology. In S. Keyser (eds.), The view from Building 20. MIT Press: Cambridge, Mass.

Izvorksi, Roumyana. 1995. A solution to the subcomparative paradox. In J. Camacho, L. Choueiri, and M. Watanabe (eds.), Proceedings of the 14th West Coast Conference on Formal Linguistics, 203-219. CSLI Publications: Stanford. 
Jaeggli, Osvaldo. 1982. Topics in Romance syntax. Foris: Dordrecht.

Jayaseelan, K.A. 1990. Incomplete VP deletion and gapping. Linguistic Analysis 20: 64-81.

Johnson, Kyle. 2001. What VP-ellipsis can do and what it can't, but not why. In Mark Baltin and Chris Collins (eds.), The handbook of contemporary syntactic theory. Blackwell: Malden, Mass.

Kay, Paul and Charles Fillmore. 1999. Grammatical constructions and linguistic generalizations: The What's $X$ doing $Y$ ? construction. Language 75:1-33.

Kayne, Richard. 1981. ECP extensions. Linguistic Inquiry 12:93-133.

Kempson, Ruth, Wilfried Meyer-Viol, and Dov Gabbay. 1999. VP ellipsis: Toward a dynamic, structural account. In S. Lappin and E. Benmamoun (eds.) Fragments: Studies in ellipsis and gapping, 227-289. Oxford University Press: Oxford.

Kennedy, Christopher. 2002. Comparative deletion and optimality in syntax. Natural Language and Linguistic Theory 20.

Kennedy, Christopher and Jason Merchant. 2000. Attributive comparative deletion. Natural Language and Linguistic Theory 18: 89-146.

Kuno, Susumu. 1981. The syntax of comparative clauses. In R. Hendrick, C. Masek, and M. Miller (eds.), Papers from the 17th regional meeting of the Chicago Linguistics Society, 136-155. Chicago Linguistics Society: Chicago, Ill.

Lasnik, Howard. 1995. A note on pseudogapping. MIT Working Papers in Linguistics 27: 143163.

Lasnik, Howard. 1999. On feature strength: Three Minimalist approaches to overt movement. Linguistic Inquiry 30: 197-217.

Lasnik, Howard and Nicholas Sobin. 2000. The who/whom puzzle: On the preservation of an archaic feature. Natural Language and Linguistic Theory 18:343-371.

Lechner, Winfried. 1998. Comparatives and DP-structure. $\mathrm{PhD}$ thesis, University of Massachusetts, Amherst.

Levin, Nancy. 1986. Main-verb ellipsis in spoken English. Garland: New York. (PhD thesis, Ohio State University, 1979.)

Liberman, Mark. 1974. On conditioning the rule of Subject Aux Inversion. In Judith Aissen and Jorge Hankamer (eds.), Papers from the 5th meeting of the North Eastern Linguistics Society, 77-91. Harvard University: Cambridge, Mass.

López, Luis. 1995. Polarity and predicate anaphora. Ph.D. thesis, Cornell University.

López, Luis and Susanne Winkler. 2002. Gapping in phases. In Kerstin Schwabe and Susanne Winkler (eds.), Title. [this volume] John Benjamins: Amsterdam.

McCloskey, James. 1979. Transformational syntax and model theoretic semantics: A case study in Modern Irish. Reidel: Dordrecht.

McCloskey, James. 1991. Clause structure, ellipsis and proper government in Irish. Lingua 85: 259-302.

McCloskey, James. 1996. On the scope of verb movement in Irish. Natural Language and Linguistic Theory 14: 47-104.

Merchant, Jason. 2000. Antecedent-contained deletion in negative polarity items. Syntax 3: 144150 .

Merchant, Jason. 2001. The syntax of silence: Sluicing, islands, and the theory of ellipsis. Oxford University Press: Oxford.

Milner, J.-C. 1978. Cyclicité successive, comparatives, et Cross-over en français (première partie). Linguistic Inquiry 9:673-693.

Pesetsky, David and Esther Torrego. 2001. T-to-C movement: Causes and consequences. In M. Kenstowicz (ed.), Ken Hale: A life in language, 355-426. MIT Press: Cambridge, Mass.

Pollard, Carl and Ivan Sag. 1994. Head-driven phrase structure grammar. University of Chicago Press: Chicago, Ill.

Postal, Paul. 1998. Three investigations of extraction. MIT Press: Cambridge, Mass.

Potsdam, Eric. 1996. Syntactic issues in the English imperative. PhD thesis, University of California, Santa Cruz. Published 1998 by Garland Press: New York.

Potts, Chris. 2000. A fragmentary, (rightly?) non-unified account of comparative and as-clause T-to-C movement. Ms., University of California, Santa Cruz. 
Quirk, Randolph, Sidney Greenbaum, Geoffrey Leech, and Jan Svartvik. 1985. A comprehensive grammar of the English language. Longman: London.

Reis, Marga. 2000. Embedded V2 and parentheticals. Paper presented at the 15th Comparative Germanic Syntax Workshop, University of Groningen. To appear in J.-W. Zwart and W. Abraham (eds.), Studies in comparative Germanic syntax, John Benjamins: Amsterdam.

Richards, Norvin. To appear. Movement in language: Interactions and architectures. Oxford University Press: Oxford.

Rizzi, Luigi. 1990. Relativized Minimality. MIT Press: Cambridge, Mass.

Sag, Ivan. 1976a. Deletion and Logical Form. PhD thesis, MIT. Published 1979 by Garland Press: New York.

Sag, Ivan. 1976b. A note on verb phrase deletion. Linguistic Inquiry 7:664-671.

Sag, Ivan. 1997. English relative clause constructions. Journal of Linguistics 33:431-484.

Sobin, Nicholas. 1981. On Adv/PP-first reductions. Linguistic Inquiry 12:488-491.

Stowell, Tim. 1981. Origins of phrase structure. PhD thesis, MIT.

Torrego, Esther. 1984. On inversion in Spanish and some of its effects. Linguistic Inquiry 15: 103-129.

Walker, Rachel. 1998. Nasalization, neutral segments, and opacity effects. $\mathrm{PhD}$ thesis, University of California, Santa Cruz. Published 2000 by Garland Press: New York.

Zwart, Jan-Wouter. 2001. Syntactic and phonological verb movement. Syntax.

Department of Linguistics

University of Chicago

1010 E. 59th St.

Chicago, IL 60637 USA

merchant@uchicago.edu

http://home.uchicago.edu/ merchant 